\title{
Analysis on the Dilemma Development Strategies of Higher Vocational Education in China
}

\author{
Yi Yang \\ Shanghai University of International Business and Economics, 201620, China \\ yangyi@suibe.edu.cn
}

\begin{abstract}
The state council meeting strongly supports the establishment of vocational schools and promotes the integration and mutual recognition of academic results between vocational education and general education. By analyzing the dilemmas and problems in the development of higher vocational schools in China, it is found that higher vocational education has long been in an awkward situation. On one hand is to provide the supply of talents for enterprises, on the other hand is to break the obstacles in the development of higher vocational schools. To put vocational schools play active role in educational field and job market is the key objective of this study.
\end{abstract}

Keywords: Higher Vocational Education; Vocational School; Dilemma; Development; Strategies.

\section{Introduction}

The past 20 years, China's vocational and technical education industry has initially established primary, secondary and higher vocational and technical schools with Chinese characteristics [1]. In the environment of China's policy of vigorously promoting the development of higher vocational education, with the increasingly aggressive implementation of the double reduction policy, $50 \%$ of students may not be able to successfully enter high school [2], in this case, technical vocational schools may become one of the options for many students and parents [3].

The core function of higher vocational education is pragmatic and career-oriented. But to some extent, it addresses the current overpopulation of our university graduates, researchers have also raised concerns that higher vocational education in China is still in its early stages and there is still a long way to go. In 1990, Dougherty found out in his research that in contrast, tuition fees at vocational schools are no cheaper than at academic high schools, and even with higher cost, but lower return [4]. In 2020, Dong et al. confirmed through their research that most students who were enrolled in higher education schools had poor academic performance in high school [5]. In 2021, Zhao argued that higher vocational education carries both internal and external tasks, and that teaching and practice in parallel are the basis of vocational education, and that the efficiency of the teaching environment, equipment, teaching content and management system should be improved in all aspects [6]. In 2019, comparing the overall level of young teachers in higher education schools and universities, Ying et al. found that the quality of young teachers in higher education schools needs to be improved in various aspects, such as teaching experience, professional identity and service consciousness, etc. In addition, higher education schools should also cultivate teachers' professionalism, academic level, teaching level and innovation spirit to improve the core competitiveness of higher education schools [7]. In 2021, Li et al. found in her study on the current situation of education and management of international students in higher education institutions that the current problems of low entry threshold, low scores, unsound organizational structure, and lagging education model of international students are all problems that plague the overall development of higher vocational education in China factors, which should be given prompt attention by the government and education departments, and measures should be designated to address and improve them on all fronts [8]. In 2021, Zhao et al. pointed out that higher vocational education was constrained by the political environment and development conditions. For a long time, vocational education has been positioned as second-rate education, which is below the level of general undergraduate education. In the job market, "first degree discrimination" is common among employers, and these are the objective reasons that restrict the development of higher vocational education [9]. 
Policy makers acknowledge the need for educational diversion policies in light of the surplus of university graduates, in which case vocational schools may see significant reform and development in the future. Wang et al. argues that the value of higher vocational education is considered to be labor utility and has been undervalued in 2019. In his research, he also finds that vocational education is more effective in terms of utility compared to academic education. Cultivating highly skilled talents can inject fresh blood into the labor market, thus providing more human resources for social industries [10]. In 2020, Hu et al. found that the combination of work and learning is a key element of higher vocational education by drawing on vocational education models from developed countries such as the German "dual system" vocational education, and that the participation of enterprises in vocational education is beneficial to both parties [11]. In 2021, Tian et al. mentioned "the complex concept of higher vocational school operation", which refers to the mixed ownership of higher education institutions as a new education model with multiple ownership subjects, such as state-owned, collective, private and foreign capital. By attracting social capital, management, and other parties to participate in talent training, vocational institutions are provided with certain funding and teacher welfare guarantees, effectively realizing the optimal allocation of social resources and improving the efficiency of resource utilization [12]. In 2021, Li et al. reported that the traditional teaching model should be reformed and more practical skills, such as internet technology, should be incorporated into teaching activities. The goal of higher vocational education is to improve highly skilled knowledge to meet the needs of the job market and to be able to work at the front line of production, construction, and service [13].

This study investigates the background and the results of Former researchers, analyzes the dilemmas and development of higher vocational institutions, and proposes targeted strategic research for the future development of higher vocational institutions in China.

\section{The Dilemmas of the Development of Vocational Education}

Among the barriers to the development of higher vocational education in China, the main concern of most students is the job prospects and salary. The overall low level of income is one of the many challenges facing vocational education. From the Ministry of Education's report on the salaries of vocational schools' graduates for 2020-2021 (Figure 1), it is cleared that, More than 57\% of graduates with income levels less that $3 \mathrm{k}$ and between $3 \mathrm{k}$ to $5 \mathrm{k}$ per month. $31.50 \%$ of graduates with income levels between $10 \mathrm{k}$ and $20 \mathrm{k}$. Only $10.5-\%$ of graduates with salaries more than $10 \mathrm{k}$.

\section{0-2021 Income distribution of graduates from higher vocational institutions}

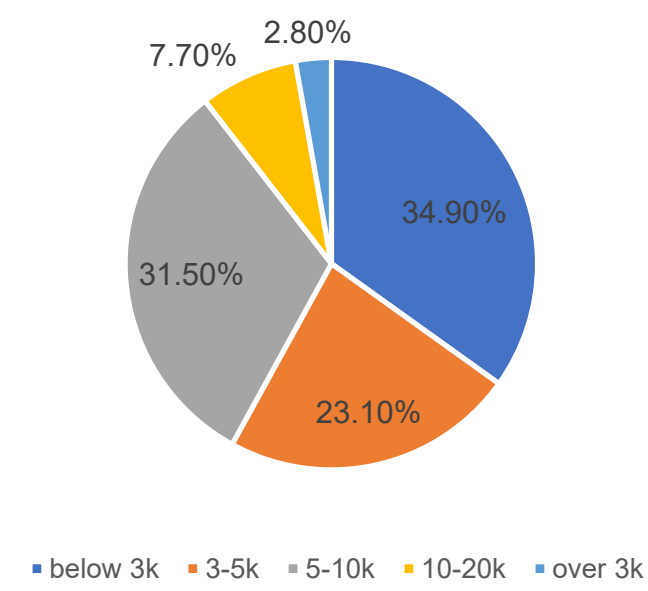

Figure 1. 2020-2021 Income distribution of graduates from higher vocational institutions 
Higher vocational schools are generally three-year programmes, with the first two years being spent at school learning theory and practical study, the third year is spent on placement in selected companies. In this process of moving from internship to formal work, many vocational school students become cheap, flexible and unprotected labor, and even have to pay agency fees and management fees to get satisfactory job recommendations. This environment also directly contributes to the worrying employment prospects of vocational school graduates, the low quality of the employment environment and the low level of salaries.

\subsection{Poor School Conditions}

Most vocational schools in China operate in poor conditions, with low technical equipment, lack of experimental space or training places, even some national model schools are not as good as the teaching equipment of private training departments, the equipment is old and out-of-date, and not updated in time. This kinds of situation also link to the shortage of funds, such as teaching buildings, dormitory buildings, cafeteria laboratories or teaching instruments and equipment, it is difficult to meet the needs for most students. Especially in the recent years, the number of students is gradually increasing, the contradiction between the development of vocational education and the limited schooling conditions and resources is still difficult to be solved in a short period of time [14].

\subsection{Crisis of Trust}

Some vocational schools have been under economic pressure due to their poor management, and thus have been engaging in "false propaganda" to attract the attention of students, but in fact, they have lowered the quality of teaching, cut teacher's and student's expenses, and even caused confusion by charging indiscriminate fees [15]. For example, under the banner of charging a fee up front and refunds at graduation, it turns out that few students receive a refund from the school by the time they graduate. There are also charge fees under the guise of many excuses and imply that students will not be issued graduation certificates unless they pay the fees. With all of those bad actions, eventually lead to the discrediting of vocational school education, forming a vicious circle in the long run.

\subsection{Low Social Identity}

China's education focuses on knowledge education, thus on some level, neglected the cultivation of students' professional skills. A concept has deeply rooted in people's mind is that vocational education is a diversion for students with poor grades. From the perspective of society and the recruitment of enterprises, parents' choice of schools and students' willingness, there is an overall prejudice against vocational education, and the general recognition is low. In reality, students graduated from vocational schools have narrow employment channels and end up in low-end supply. The State Council has pointed out in many meetings to vigorously carry out vocational quality education, but it has never been able to reverse the traditional thinking of parents and students [16].

\subsection{Poor Quality of Teaching}

Teaching contents, old methods and single teaching mode are an important factor that block the quality of teaching in vocational schools. Most of the professional construction is still subjectoriented, while the purpose of vocational education should have been based on the direction of practical skills training. However, many vocational schools only focusing on theoretical education, while production practice, social services, promotion, and upgrading of skills are not well integrated with theory. The goal and direction of training lags behind the demand of talent supply for social development [17].

\subsection{Chaotic Management and Shortage of Qualified Teachers}

There is a severe shortage of teachers in vocational colleges in China, and there is a historical factor that the treatment of teachers in vocational colleges is lower than that in higher education institutions, which has caused the loss of a large number of excellent teachers, and also indirectly led 
to the low education level of teachers in vocational colleges in general. Professional quality and ideological and political quality cannot meet the normal demand, such as a vicious circle of one loop after another eventually makes it difficult for higher vocational colleges to bring in the needed teaching talent. More because of the problems in the personnel system, it's hard to provide tenured position for most teachers.

\subsection{Good and Bad Students Mix in Vocational Colleges}

After graduation, students are admitted to all levels of schools in order of their scores, those with good grades are going to key universities, those with average grades going to regular universities, those with poor grades going to vocational institutions. Due to the chaos of many vocational schools internal functions, many teachers are forced to take up the task of enrollment, and even deduct salary and bonus if they do not complete the enrollment task, which directly causes a phenomenon that regardless of the students qualifications, as long as they meet the enrollment requirements or pay the fees, they can study in a vocational school. Under such a policy, vocational schools become a shelter for students with poor scores [18].

\section{Future Development Strategies of Vocational Education}

In fact, in the past two years, China's higher vocational institutions have made good progress in terms of infrastructure, faculty strength or the number of students enrolled. According to the data in Figure 2, China's higher vocational institutions reached 1,423 in 2019, five more than the previous year, and the number of students enrolled also increased by $30 \%$. This shows that there is great potential for the future development of higher vocational education market in China.

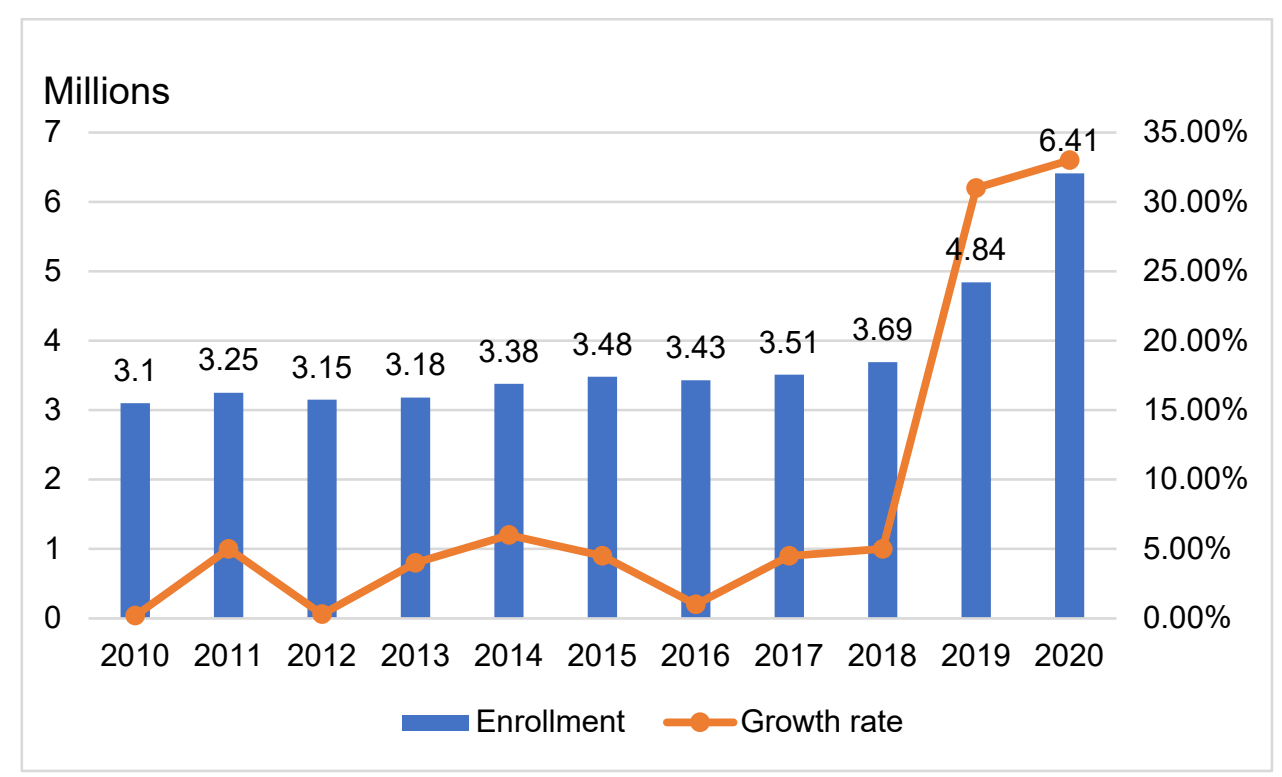

Figure 2. China's higher vocational institutions from 2010 to 2020

Although the employment rate is still severe, higher vocational colleges cultivate front-line grassroots technical application talents, mostly focusing on practical operation, the knowledge structure is in line with their specialty. Therefore students with strong hands-on skills, professionalism and plasticity stand out in the recruitment market, which is also the advantage of higher vocational school graduates. Guide graduates to really play a role in job industry, promote hands-on practical skills, establish correct employment values and enhance their employment competitiveness, the overall value of higher vocational education can certainly be taken to a higher level in the future. However, the problems still remaining and need to be solved. 


\subsection{Combination of Industry and Education}

The development of higher vocational education shouldn't stay in a rut. In economically developed regions such as Shanghai, some companies have opened joint training mechanisms with vocational schools [19]. For example, the Tesla Shanghai factory, where vocational schools will supply talents direct for companies such as Tesla, aiming at the construction of the integration of industry and technical education, the project will form a comprehensive function of talent training, industrial services, scientific research, and practical training. On the other hand, foreign experience can be drawn upon to establish world-class Industrial colleges and learning factories [20]. By turning the existing 'internship factories' into 'learning factories', institutions can have an experimental learning and testing base. The two parties should work together and complement each other's strengths to promote cross-border talent connections.

\subsection{Teaching Environment and Equipment Upgrade}

The upgrading of teaching environment and equipment is a hard standard for improving vocational education in China. First must continue to increase the investment in vocational school education, completely eradicate the current school conditions of dilapidated, old and dangerous school buildings, and change the status quo of outdated equipment. Really provide reliable infrastructure for quality education, build a better teaching and learning environment for teachers and students, make teachers and students more willing and active in teaching and learning activities. Strengthen the construction of teaching instruments, establish a more complete and functional experimental practice base [21].

\subsection{Blow the False Propaganda of Vocational Schools}

False propaganda and other irregular enrollment behaviors in vocational schools have been common for a long time. To promote the long-term and stable development of vocational schools, it is necessary to conduct a comprehensive sweep of irregular false enrollment, focusing on whether there is false propaganda, false promises, deceptive enrollment, paid enrollment, illegal joint schooling, etc. To strictly review the enrollment publicity materials printed by each school and strengthen the supervision of the qualification of each student [22]. Once irregularities are found, we must immediately call a halt and impose rectification. Vocational school must have zero tolerance attitude to strictly punish the irregularities in the admission process [23].

\subsection{Enhancing the Value of Vocational Education}

The value of vocational education is closely related to the competitiveness in the job market, and how to improve the value of vocational education depends on the reform of the teaching methods, school operation mode, management system and guarantee mechanism, so it is imperative to optimize the supply structure of vocational education [24]. Schools should be encouraged to open more majors to meet the shortage and market demand, form a professional system that closely matches the industrial chain, leading enterprises should be encouraged to establish vocational education, if it is combined with economic restructuring and job demands of enterprises, it can fully fulfill its value in the educational market.

\subsection{Reform of Teaching Quality}

Modern vocational education should emphasize innovative and efficient teaching methods, which requires teachers to be observant of students' learning characteristics and understanding their needs in daily practice, and to use different forms of teaching methods to stimulate students' interest and attention, based on the analysis of professional course contents. The core of higher vocational school is the degree of integration between vocational education and the needs of the market economy, aiming to combine industry and education, the main task is to improve the overall quality of students and improve the employment rate. The professional curriculum should also have a certain degree of 
relevance that combined with the practical employment needs, so that students understand the production and manual work of enterprises [25].

\subsection{Improve Management and Strengthen the Faculty Building}

The development of vocational education depends to a large extent on a high-quality faculty team. To promote the formation of a high-quality faculty, it is necessary to improve the management mechanism that is conducive to the construction of the faculty team. If teachers lack enthusiasm and initiative, the achievement of educational goals will be seriously affected. The personnel and financial powers of higher vocational institutions should be subdivided and shifted down to the Subordinate school. Teachers should only focus on the implementation of teaching jobs, should not be responsible for administrative work other than teaching. Teachers should also be encouraged to go to enterprises for internship, and establish policies to evaluate teachers' titles, qualification certification and assessment [26]. Vocational school should also actively encourage teachers to pursue further study in colleges and universities, provide teachers with certain funding and financial support.

\section{Summary}

One of main purpose of higher vocational education is to upgrade their professional knowledge and application of practical ability, in order to improve their competitiveness of employment. The traditional teaching mode is out of date, so we should keep searching for new teaching modes, the reformation of rules pave the way for the future development of higher vocational education industry. In practice, the market mainstream force should be deeply involved in the design and joint research of higher vocational and technical courses, thus forming a new ecology of symbiosis and coprosperity between the education chain, talent chain, industry chain and innovation chain. Both sides should be demanded in both directions, opening up the channel between the market and education, precisely to achieve the real goal for high quality development of higher vocational education. For a long time, higher vocational education has been caught in a dilemma of "disconnected education", which makes it difficult to achieve higher recognition and attractiveness. This study found that very few higher vocational schools in China have program that are geared to the jobs of their counterparts, and some students learn skills that are not competitive in the marketplace, making them useless.

China today is a trillion-dollar super market and the talents cultivation cannot rely on a single level of vocational education, it needs to establish a complete modern of higher vocational education system. Therefore, constantly promoting the development and improving the quality of higher vocational schools in all aspects, this is the key issues that need to be focused on now. What need to be done is to truly enhance the efficiency of education resource allocation, qualification and other initiatives, promote the improvement of higher vocational school education environment and equipment upgrade, strengthen troop's construction, and remove the unnecessary academic-only institutional arrangements. And innovate the teaching mode, achieve expansive learning, the practice leads the teaching, at the same time, the teaching also urges the practice, so that students can improve their professional skills in practice.

\section{References}

[1] Xuelian Chen, Wei Zhou. Research on Moral Education and Ideological Leadership of Higher Vocational Students under the New Media Environment[C]/Proceedings of 2nd International Conference on Humanities, Arts, and Social Sciences (HASS 2021).,2021: 430-434. DOI: 10. 26914/ c. cnkihy. 2021. 030129.

[2] Ollikainen Jani-Petteri, Karhunen Hannu A tale of two trade-offs: Effects of opening pathways from vocational to higher education[J] Economics Letters, 2021, 205.

[3] Yan, Liping, and Yanzhi Peng. "Development of Strategic Industrial Clusters in Guangdong Higher Vocational Colleges Based on the 'Double High Plan." Journal of Contemporary Educational Research, vol. 5 , no. 6,30 June 2021 , pp. 8-13. 
[4] C.R.S. Dougherty. Unit costs and economies of scale in vocational and technical education: evidence from the People's Republic of China Econ. Educ. Rev., 9 (4) (1990), pp. 389-394.

[5] Dong Guo, Anyi Wang. Is vocational education a good alternative to low-performing students in China [J] International Journal of Educational Development, 2020, 75(C).

[6] Peiliu Zhao. Some Thoughts on The Multi-Dimensional Promotion of The Development Quality of Higher Vocational Education By "Double High Plan"[J]. International Journal of Higher Education Teaching Theory, 2021, 2(1).

[7] Ying Zhang. Research on the Enhancement of the Ability of Young Teachers in Higher Vocational Colleges[J]. Advances in Higher Education, 2019, 3(4).

[8] Li Qiaoning. Study on the Current Situation and Countermeasures of Education Management of International Students in Higher Education Institutions[J]. Modern Vocational Education (in Chinese), 2021 (49):132-134.

[9] Zhao Hui. Perspectives on the social acceptance of vocational education[J]. Educator (in Chinese), 2021 (33): 8-9.

[10] Wang Mingjun. Measurement of Labor Utility Value of Vocational Education and Academic Education from the Perspective of Big Data--1778051 Individual Samples Based on CHARLS Database[C]. AEIC Academic Exchange Information Centre (China). Proceedings of 4th International Conference on Humanities Science, Management and Education Technology (HSMET 2019) (Advances in Social Science, Education and Humanities Research, VOL.334). AEIC Academic Exchange Information Centre (China): International Conference on Humanities and Social Science Research, 2019:518-527.

[11] Liang Hu Research and Practice on Effective Path of Enterprise Participation in Vocational Education[J] Journal of Physics: Conference Series, 2020, 1549(4).

[12] Tian Weina, Zhang Yingfan. Research on the Construction of Internal Quality Assurance System for Talent Cultivation under the Mixed Ownership Model of Higher Education Institutions[J]. Modern Vocational Education (in Chinese), 2021(49):38-39.

[13] Feiyan Li. Construction and Evaluation of Blended Teaching Mode of Practical Courses in Higher Vocational Education [A]. Wuhan Zhicheng Times Cultural Development Co., Ltd. Proceedings of 2021 International Conference on Business Management, Humanities and Education Engineering (BMHEE 2021) [C]. Wuhan Zhicheng Times Cultural Development Co., Ltd.: Wuhan Zhicheng Times Culture Development Co, 2021:11.

[14] Lu Weifeng. Analysis of the dilemma and countermeasures of enrollment in higher vocational colleges in the new era [J]. Technology \& Management (in Chinese), 2020(06):71.

[15] Yang Deguang. The inspiration higher vocational education in Taiwan[J]. Research in Educational Development (in Chinese). 2000(08).

[16] Roll Michael, Ifenthaler Dirk Learning Factories 4.0 in technical vocational schools: can they foster competence development? [J] Empirical Research in Vocational Education and Training, 2021, 13(1).

[17] Ariyani Linda Fauziyah, Widjaja Sri Umi Mintarti, Wahyono Hari et al. Vocational education phenomena research method [J] MethodsX, 2021, 8.

[18] Research on Talent Training of Veterans' Educational Enhancement Plan Under Higher Vocational Expansion[A]. Chibing Gong. Proceedings of 2021 International Scientific Conference on Innovative Education (ISCIE 2021) [C]. 2021.

[19] On Higher Vocational College Students Entrepreneurship Competence Cultivation Reform--Based on Comparative Perspective in Entrepreneurship Education Between Canada and China[A]. Tiwen Han, Zhaohui Yang, Duo Bai. Proceedings of 2021 6th International Conference on Education Reform and Modern Management (ERMM2021) [C]. 202.

[20] Hordern Jim Higher apprenticeships in England: professional and vocational formation[J] International Journal of Training Research, 2015, 13(3).

[21] Chen Xiaobo. Some thoughts on the development of higher vocational education[J]. Practice and Theory of SEZS (in Chinese). 1996(06).

[22] Li Jian. How vocational education can get out of difficulty[J]. Policy \& Scientific Consult (in Chinese). 2005 (05). 
[23] Chen Yanfei. The dilemma of innovation development in higher vocational education and the exploration of strategies[J]. Research on Transmission Competence (in Chinese), 2020,4(17):134-135.

[24] Sang Lei. Analysis of professional core literacy and value in the interaction between career and education [J]. Journal of Vocational Education (in Chinese), 2020,36(10):13-19.

[25] Construction and Evaluation of Blended Teaching Mode of Practical Courses in Higher Vocational Education[A]. Feiyan Li. Proceedings of 2021 International Conference on Business Management, Humanities and Education Engineering (BMHEE 2021) [C]. 2021.

[26] Yao Yanqin. Discussion on the faculty building of vocational education[J]. Journal of Yanan College of Education (in Chinese), 2008(01):32-33. 